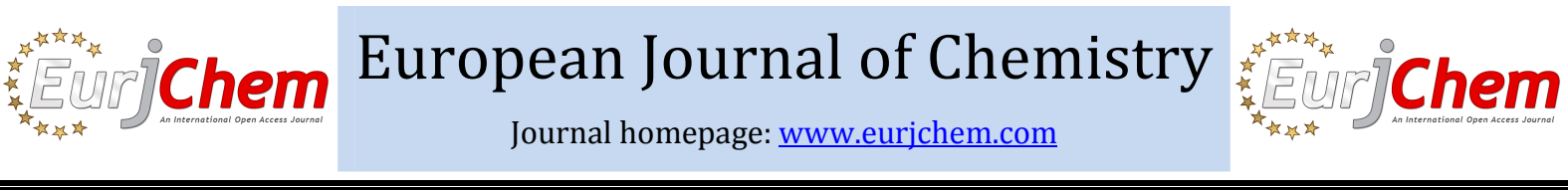

\section{Spectrofluorometric determination of linagliptin in bulk and in pharmaceutical dosage form}

\author{
Ramzia Ismail El-Bagary a, Ehab Farouk Elkady a, and Bassam Mahfouz Ayoub b,* \\ a Pharmaceutical Chemistry Department, Faculty of Pharmacy, Cairo University, Cairo 11562, Egypt \\ b Pharmaceutical Chemistry Department, Faculty of Pharmacy, British University in Egypt, El-Sherouk City, Cairo 11837, Egypt \\ *Corresponding author at: Pharmaceutical Chemistry Department, Faculty of Pharmacy, British University in Egypt, El-Sherouk city, Cairo 11837, Egypt. \\ Tel.: +2.01.225104337. Fax: +2.02.24148452. E-mail address: bassam.ayoub@bue.edu.eg (B.M. Ayoub).
}

\section{COMMUNICATION INFORMATION}

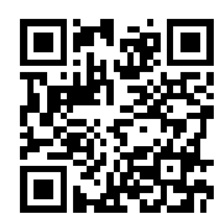

DOI: 10.5155 /eurjchem.5.2.380-382.845

Received: 04 June 2013

Received in revised form: 26 July 2013

Accepted: 18 August 2013

Online: 30 June 2014

\section{KEYWORDS}

\section{Tradjenta}

Linagliptin

Fluorometry

DPP-4 Inhibitors

Statistical analysis

Pharmaceutical preparation

\section{Introduction}

Linagliptin, 8-[(3R)-3-aminopiperidin-1-yl]-7-(but-2-yn-1yl)-3-methyl-1-[(4-methylquinazolin-2-yl)methyl]-3,7-dihydro$1 \mathrm{H}$-purine-2,6-dione] (Figure 1) is a new hypoglycemic drug that belongs to dipeptidyl-peptidase- 4 inhibitor class which stimulates glucose-dependent insulin release [1,2]. DPP-4 inhibitors represent a new therapeutic approach to the treatment of type 2 diabetes that functions to stimulate glucose-dependent insulin release and reduce glucagons levels. This is done through inhibition of the inactivation of incretins, particularly glucagon-like peptide-1 (GLP-1) and gastric inhibitory polypeptide (GIP) [1,2]. Only one method has been described for the determination of LNG in its pharmaceutical preparation [3].<smiles>CC#CCn1c(N2CCC[C@@H](N)C2)nc2c1c(=O)n(Cc1nc(C)c3ccccc3n1)c(=O)n2C</smiles>

Figure 1. Chemical structure of linagliptin.
The aim of the present work was to develop a spectrofluorometric method for the determination of LNG based on the native fluorescence of the drug. Spectrofluorometry has long been applied in the field of pharmaceutical analysis of many drugs [4-7] because of the higher sensitivity than is attainable in absorption spectrophotometry. A necessary condition for a compound to fluoresce is that it absorbs light in the UV or visible region of the spectrum. Accordingly, compounds that have a conjugated $\pi$ electron system may give efficient re-emission of the absorbed energy as a direct method for the determination in which the native fluorescence of the molecule is measured [4-7].

\section{Experimental}

\subsection{Instrumentation}

A Shimadzu RF-1501 spectrofluorimeter (Japan) was used.

\subsection{Reagents and reference samples}

Pharmaceutical grade LNG, certified to contain $99.80 \%$, tradjenta ${ }^{\circledR}$ tablets nominally containing $5 \mathrm{mg}$ of LNG per tablet were supplied from Eli Lilly and company (USA). 
Table 1. Results obtained by the proposed fluorometric method for the determination of linagliptin.

\begin{tabular}{l|l|}
\hline$\lambda_{\max }$ excitation of measurements, $\mathrm{nm}$ & 339 \\
$\lambda_{\max }$ emission of measurements, $\mathrm{nm}$ & 435 \\
Linearity, $\mu \mathrm{g} / \mathrm{mL}$ & $10-110$ \\
\hline Regression equation & $\mathrm{F}_{435}=1.0534 \mathrm{C}_{\mu \mathrm{g} / \mathrm{mL}}-0.183$ \\
Regression coefficient $\left(r^{2}\right)$ & 0.9999 \\
$\mathrm{LOD}, \mu \mathrm{g} / \mathrm{mL}$ & 0.84 \\
$\mathrm{LOQ}, \mu \mathrm{g} / \mathrm{mL}$ & 8.01 \\
$\mathrm{~S}_{\mathrm{b}}$ & $3.8 \times 10^{-3}$ \\
$\mathrm{~S}_{\mathrm{a}}$ & 0.32 \\
Confidence limit of the slope & $1.0534 \pm 0.34$ \\
Confidence limit of the intercept & $-0.183 \pm 7.03 \times 10^{-4}$ \\
\hline Standard error of the estimation & 0.32 \\
Drug in bulk & $100.30 \pm 0.93$ \\
Drug in dosage form (Tradjenta $\left.{ }^{\circledR}\right)$ & $99.83 \pm 0.56$ \\
\hline Drug added & $100.05 \pm 0.92$ \\
\hline F*: Relative fluorescence. &
\end{tabular}

F*: Relative fluorescence.

LOD: Limit of detection, LOQ: Limit of quantification.

Table 2. Statistical comparison between the results of the fluorometric method and the reference method for the determination of linagliptin

\begin{tabular}{|c|c|c|}
\hline Statistical term* & Reference Method ** & Drug in bulk \\
\hline Mean & 99.45 & 100.30 \\
\hline S.D. & 1.34 & 0.93 \\
\hline S.E. & 0.60 & 0.42 \\
\hline \%R.S.D. & 1.35 & 0.93 \\
\hline $\mathrm{n}$ & 5 & 5 \\
\hline V & 1.80 & 0.86 \\
\hline $\mathrm{t}(2.306)^{* * *}$ & & 1.20 \\
\hline
\end{tabular}

Standard stock solutions of LNG ( $1 \mathrm{mg} / \mathrm{mL}$ ) were prepared by dissolving $100 \mathrm{mg}$ of the drug in acetonitrile:methanol, $(90: 10, v: v)$ and completing the volume to $100 \mathrm{~mL}$ in a volumetric flask and then the required concentrations were prepared by serial dilution. All the solvents used were of analytical grade.

\subsection{General procedure and calibration graph}

Aliquots from LNG stock standard solution equivalent to 100-1100 $\mu \mathrm{g}$ were accurately measured and transferred into a set of $10 \mathrm{~mL}$ volumetric flasks and the volumes were completed with acetonitrile:methanol, $(90: 10, \quad v: v)$. The relative fluorescence intensity was measured at the specified excitation and emission wavelengths $\left(\lambda_{\mathrm{em}}\right.$ at $435 \mathrm{~nm}$ with $\lambda_{\mathrm{eX}}$ at $339 \mathrm{~nm}$ (Figure 2)), then plotted against its corresponding concentration and the regression parameters were computed.

\subsection{Assay of LNG in bulk}

The relative fluorescence intensity of LNG in bulk was measured at the specified excitation and emission wavelengths ( $\lambda_{\text {em }}$ at $435 \mathrm{~nm}$ with $\lambda_{\text {ex }}$ at $339 \mathrm{~nm}$ ) with the concentration range $20-100 \mu \mathrm{g} / \mathrm{mL}$.

\subsection{Assay of Tradjenta ${ }^{\circledR}$ tablets}

Twenty tablets were weighed and the coats were removed by carefully rubbing with a clean tissue wetted with methanol. An accurately weighed amount of the finely powdered tablets equivalent to $100 \mathrm{mg}$ of LNG were made up to $100 \mathrm{~mL}$ with acetonitrile:methanol, $(90: 10, v: v)$, the solution was filtered followed by serial dilution to the required concentration. The procedure was continued as mentioned under general procedures and calibration.

\section{Results and discussion}

Literature survey reveals that only one method has been described for the determination of LNG in its pharmaceutical preparation [3]. The development of spectrofluorometric method for the determination of LNG was of interest as no such methods have been reported.

\subsection{Quantification, accuracy and precision}

Standard calibration curves were prepared by separately preparing series of different concentrations and applying the suggested procedures. The linearity of the calibration curve was validated by the high value of correlation coefficient. The analytical data of the calibration curve including standard deviations for the slope and intercept $\left(S_{b}, S_{a}\right)$ are summarized in Table 1. The regression equation of the calibration graph was utilized for the determination of concentrations of LNG in bulk and tablets. The reproducibility and accuracy of the suggested method were assessed using different concentrations of LNG in bulk and determination of the concentrations in tablets. The results obtained were of good accuracy and precision. The applicability of the procedure for estimation of tablets was validated using standard addition technique as a check for accuracy (Table 1).

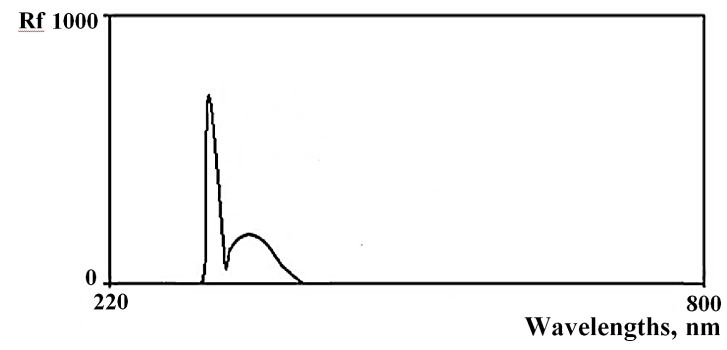

Figure 2. Excitation and emission spectra of linagliptin $(100 \mu \mathrm{g} / \mathrm{mL})$.

A statistical analysis of the results obtained by the proposed method for the determination of LNG was carried out by "SPSS statistical package version 11". The significant difference between groups was tested by one way ANOVA (Ftest) at $p=0.05$ as shown in Table 2 . The test ascertained that there was no significant difference among the methods. 


\section{Conclusion}

The proposed method has the advantages of simplicity, precision, accuracy and convenience for the quantitation of LNG. The proposed method can be used for the quality control of LNG and can be extended for routine analysis of LNG in its pharmaceutical preparation.

\section{References}

Kirby, M.; Yu, D.; Conor, S. Clin. Sci. 2010, 118, 31-41.

Sekaran, B.; Rani, P. Int. J. Pharm. Pharm. Sci. 2010, 2, 138-142.

Lakshmi, B.; Reddy, T. J. Atom. Mol. 2012, 2, 155-164.

El-Ashry, S.; El-Sherbeny, M.; El-Sherbeny, D. J. Pharm. Biomed. Anal. 2000, 22, 729-737.

Rizk, M.; Belal, F.; Ibrahim, F. Pharm. Acta Helv. 2000, 74, 371-377.

Belal, F.; Ibrahim, F.; Hassan, S. Anal. Chim. Acta 1991, 255, 103-106.

Bebawy, L.; Abbas, S.; Fattah, L.; Refaat, H. Il Farmaco 2005, 60, 859867. 